\title{
ACERCA DE LA FUNDAMENTACIÓN DE LAS EXIGENCIAS DE CUIDADO*
}

On the grounding of care requirements

Urs Kindhäuser ${ }^{* *}$

Resumen: El artículo indaga en la función que las así llamadas "exigencias de cuidado" (Sorgfaltsanforderungen) cumplen en la fundamentación de la responsabilidad penal a título de imprudencia. Para ello, propone una reconstrucción analítica del delito fundada en las nociones de norma, deber y acción, la que permite trazar una clara distinción entre el quebrantamiento de una o más normas de comportamiento como objeto del juicio de imputación (a título de imprudencia), y la inobservancia de una o más exigencias de cuidado como criterio de fundamentación de dicho juicio. Finalmente, y sobre esa base, el artículo examina el rol que le cabe al concepto de riesgo permitido y a la consideración de las circunstancias individuales del autor en la fundamentación de las exigencias de cuidado.

Palabras clave: imprudencia - exigencias de cuidado - norma - deber - acción - riesgo permitido.

Abstract: The article inquires into the function of the so called "care requirements" (Sorgfaltsanforderungen) within the grounding of negligent criminal liability. For that purpose, it offers an analytical reconstruction of crime based on the notions of norm, duty and action, which allows to make a clear distinction between the violation of a norm, as the object of the imputation of (negligent) criminal liability, and the non-observance of a care requirement, as a grounding criterion of such imputation. Finally, and on this ground, the article examines the role played by the concept of "tolerable risk" (riesgo permitido) and by the individual circumstances of the wrongdoer in the grounding of care requirements.

Keywords: negligence - care requirements - norm - duty - action - tolerable risk.

\section{Observación preliminar}

Las exigencias de cuidado juegan un rol en varios niveles de la constitución del delito, y ya siempre que la atribución de responsabilidad hace referencia a capacidades, verbigracia tratándose de la evitabilidad de un error de prohibición o de una situación de estado de necesidad exculpante. En lo que sigue, y a modo de

\footnotetext{
* Traducción del profesor doctor Juan Pablo Mañalich Raffo.

** Doctor en Derecho en la Albert-Ludwigs-Universität Freiburg. Venia Legendi por la AlbertLudwigs-Universität Freiburg. Catedrático y Director del Instituto de Derecho Penal de la Rheinische Friedrich-Wilhelms-Universität Bonn. Profesor honorario de la Universidad de Piura. Doctor honoris causa en la Universidad de Huánuco. Correo electrónico: kindhauser@uni-bonn.de Este artículo fue recibido el 8 de octubre de 2014, siendo aprobada su publicación el 19 de diciembre de 2014.
} 
ejemplo, se examinará el significado de las reglas de cuidado para la imprudencia, en tres pasos: ${ }^{1}$

(1) Por de pronto se revisará en general la relación entre norma e imputación en la constitución de un hecho punible.

(2) Luego se considerará más de cerca la conexión entre norma de comportamiento y exigencia de cuidado en la imprudencia.

(3) Finalmente, se echará un vistazo a la fundamentación de las exigencias de cuidado.

\section{Acerca de la construcción dogmática del hecho punible}

1. Por "hecho punible" cabe entender la responsabilidad jurídico-penal por un determinado comportamiento prohibido. Con arreglo a esto, un hecho punible se constituye con ayuda de dos sistemas de reglas: por una parte, aquellas reglas que enuncian las condiciones bajo las cuales ha de considerarse prohibido un comportamiento; y por otra, aquellas reglas que enuncian las condiciones bajo las cuales se atribuye responsabilidad por ese comportamiento prohibido. ${ }^{2}$

Las reglas con arreglo a las cuales un comportamiento es juzgado como prohibido o permitido poseen, en términos de la lógica del lenguaje, un carácter prescriptivo, y pueden ser denominadas "normas de comportamiento". En este sentido, los tipos delictivos de la parte especial pueden ser interpretados como normas que formulan el comportamiento respectivamente prohibido. Así por ejemplo, del tipo del homicidio puede inferirse la prohibición de matar a otro.

Estas normas de comportamiento indican, únicamente, qué formas de comportamiento se encuentran prohibidas u ordenadas. Ellas no indican, sin embargo, en qué medida el destinatario de la norma queda vinculado por esta, esto es, en qué medida se espera de él que ejercite sus capacidades para un comportamiento normativamente adecuado. Así, la prohibición del homicidio no indica qué es lo que el destinatario de la norma tiene que saber y qué tiene que ser físicamente capaz de hacer, para así evitar dar muerte a otro ser humano. La respuesta a esta pregunta la dan, en cambio, las reglas de imputación jurídicopenal. Se trata de reglas que determinan bajo qué presupuestos alguien puede ser hecho responsable por un determinado comportamiento prohibido.

Mientras las normas de comportamiento persiguen la protección de bienes jurídicos frente a su lesión o puesta en peligro, las reglas de imputación se encuentran orientadas a la finalidad de la pena. Pues ellas constituyen la culpabilidad del autor, a la que se encuentra referida la pena. De acuerdo con la

\footnotetext{
${ }^{1}$ Las reflexiones que siguen se limitan -en la brevedad requerida- a preguntas elementales de la teoría de las normas. Acerca de las "insuficiencias del delito de imprudente", que aquí no se consideran, véase SCHÜNEMANN (2002), pp. 37 ss.

${ }^{2}$ Acerca de la distinción entre reglas de imputación y normas, HRUSCHKA (1991), pp. 449 ss.
} 
actualmente predominante teoría de la prevención general positiva, el fin de la pena consiste en la imposición de la vigencia fáctica de las normas de comportamiento del derecho penal. Una norma exhibe vigencia fáctica si ella es seguida en la medida suficiente para servir como esquema de orientación en una sociedad. En otras palabras, la vigencia fáctica es la expectativa cognitivamente fundamentada de que una norma será reconocida, en alta medida, como vinculante para la acción, de modo tal que uno pueda confiar en el correspondiente comportamiento de los demás en la planificación de sus propias acciones. Así, ha de imponerse pena si el destinatario de la norma expresa, mediante su comportamiento, que él no quiere seguir la norma, es decir, que esta no es vinculante para él. Por intermedio de la punición se declara, entonces, que el ordenamiento jurídico no acepta esta contradicción de la norma y que la generalidad puede seguir confiando en su carácter vinculante. ${ }^{3}$

El presupuesto del reconocimiento de una norma por medio de su seguimiento es la capacidad del destinatario de realizar en el hecho lo que es debido como si fuera querido. Por de pronto, el destinatario tiene que estar en posición, física y cognitivamente, de realizar lo debido. Ello significa, tratándose por ejemplo, de la prohibición del homicidio, que él tiene que saber que puede causar la muerte de otro ser humano por medio de un comportamiento, así como tiene que ser capaz de evitarlo, desde un punto de vista físico. Asimismo, él tiene que poder reconocer lo debido y poder convertirlo, psíquicamente, en el motivo dominante de su actuar. Para seguir con el ejemplo: él tiene que saber que está prohibido causar la muerte del ser humano en cuestión. Y él tiene que disponer de la capacidad de formarse la intención, en pos del seguimiento de la norma, de evitar el comportamiento mortal. En otras palabras, él tiene que ser capaz de controlar su comportamiento mediante una motivación conforme a la norma.

La capacidad cognitiva y física de realizar un determinado objetivo puede ser denominada "capacidad de acción"; y la capacidad de formarse una intención, en pos del seguimiento de una norma, "capacidad de motivación". En referencia a estas dos capacidades es atribuida la responsabilidad jurídico-penal. La vinculación del destinatario a la respectiva norma de comportamiento, con arreglo a su capacidad de acción, puede ser denominada "deber", y su vinculación al deber, con arreglo a su capacidad de motivación, "capacidad de culpabilidad". A estos dos pasos de imputación corresponde la diferenciación de injusto y culpabilidad en la construcción más tradicional del delito. ${ }^{5}$

\footnotetext{
${ }^{3}$ Esta breve referencia -cfr. también KINDHÄUSER (2013), pp. 38 s., 48 s.- puede ser suficiente aquí, ya que no cabe enterar en el altamente controversial campo de la teoría de los fines de la pena y las posiciones discrepantes no deberían tener impacto en el contenido de las reglas de imputación.

${ }^{4}$ En tal medida, las normas son fundamentos de obligaciones para acciones, fundamental RAZ (2006), p. 33 y passim.

${ }^{5}$ Esta diferenciación de ninguna manera es solo didácticamente sensata, sino que está fundada en la lógica de los pasos de imputación.
} 
2. La vinculación de un destinatario de la norma a esta según su capacidad de acción, que interesa en nuestro contexto, se deja ilustrar con ayuda de un silogismo práctico. ${ }^{6}$ Esta inferencia está formalmente construida a semejanza del esquema de un silogismo lógico. ${ }^{7}$ En la premisa mayor, él designa el objetivo perseguido por una persona, esto es, su objeto intencional. La premisa menor formula los conocimientos de la persona que tienen relevancia para la consecución de su objetivo mediante una acción. Y en la conclusión se designa la acción que, según su estado de conocimientos, la persona tiene que ejecutar u omitir para alcanzar su objetivo. La inferencia tiene, de este modo, la siguiente forma general:

Premisa mayor: una persona P quiere conseguir $x$.

Premisa menor: P asume que ella solo puede alcanzar $x$, si ella hace $y$.

Conclusión: Entonces, $\mathrm{P}$ tiene que hacer $y$.

En esta inferencia, la conclusión no está conceptualmente condicionada, sino que se refiere a los elementos intelectuales y volitivos de las acciones. ${ }^{8}$ Ella se obtiene a partir de la conexión práctica entre finalidad y medio e implica, con ello, una necesidad práctica. Es evidente que una persona que quiere alcanzar $x$, y que sabe si que para esto ella puede y tiene que hacer $y$, se comportaría de modo contradictorio e incomprensible si ella no hace $y$.

3. Para un ciudadano leal a derecho, que pretende seguir las normas jurídicopenales, el silogismo práctico tendría el siguiente contenido:

Premisa mayor: A quiere no realizar el tipo $x$ a través de su actuar.

Premisa menor: A sabe que él (probablemente) realizará $x$ si él hace $y$.

Conclusión: Entonces, A tiene que omitir hacer $y$.

Si una persona hace $y$, a pesar de que, con arreglo a la premisa menor, ella sabe que si hace $y$ (probablemente) realiza $x$, entonces la evitación de $x$ no es lo que ella quiere. En otras palabras, él no reconoce lo debido, según la norma, como razón vinculante para su actuar, contradiciendo así las exigencias de la norma. El conocimiento indicado en la premisa menor por ella autoriza a considerar el comportamiento del autor como una infracción de deber. Pues este conocimiento capacitaba al autor para evitar la realización del tipo.

Es adecuado designar el conocimiento indicado en la premisa menor como dolo. Lo efectivamente querido por el autor, en cambio, no juega rol alguno. Pues con independencia de lo que el autor haya querido alcanzar con su comportamiento, precisamente no era la evitación de la realización del tipo. Por

${ }^{6}$ VON WRIGHT(1977), pp. 42 ss.

${ }^{7} \mathrm{Al}$ respecto EsSLER(1969), pp. 41 ss.

${ }^{8}$ Según KANT: Metaphysik der Sitten, B 44-45, en relación con semejante inferencia se trata de un principio analítico de la voluntad. Una interpretación analítica de la conclusión exige, empero, una definición sumamente estrecha de "querer". 
qué el autor no quiso evitar la realización del tipo, a pesar de haber contado con el conocimiento necesario para ello y de que la norma tendría que haber sido su motivo dominante, es, por contrapartida, una pregunta de la culpabilidad. Tal vez, el autor no podía formarse la voluntad de evitar la realización del tipo, porque estaba alienado o privado de razón, o bien porque se encontraba en una situación de estado de necesidad. En cualquier caso, él sí era capaz de acción en pos del seguimiento de la norma; y esto es suficiente para la fundamentación del injusto.?

4. El silogismo práctico se deja aprovechar con mucha facilidad para explicar y precisar la imputación a título de dolo. Habiendo dolo, al autor se imputa la realización de un tipo de prohibición como infracción de deber, porque él habría podido evitar la realización del tipo, si él así lo hubiese querido. Con ello, el autor doloso pone de manifiesto que él no quiere seguir la norma, esto es, que la norma no constituye una razón vinculante para su actuar. A este respecto, el autor tiene que considerar que la realización del tipo, a consecuencia de su comportamiento, es en tal medida probable que, en tanto ciudadano que practica la fidelidad derecho y decide racionalmente, él tendría que evitar incondicionadamente este comportamiento. ${ }^{10}$ En otras palabras, el autor ha de partir de la base de que, en las circunstancias dadas, el comportamiento en cuestión fundamentaría el riesgo concreto de una realización del tipo. ${ }^{11}$

\section{Norma de comportamiento y exigencia de cuidado}

1. Si una persona yerra acerca del riesgo concreto, asociado a su comportamiento, de la realización de un tipo, o bien si reconoce ese riesgo recién en un momento en el cual ella ya no puede adoptar una alternativa de comportamiento, entonces en principio su comportamiento no puede ser visto como una infracción de deber. Nadie está obligado más allá de su propia capacidad: ultra posse nemo obligatur. ${ }^{12}$

\footnotetext{
9 Cabe mencionar de paso que aquí aparece el problema, ya discutido por la teoría de los imperativos (cfr. HOLD VON FERNECK (1903), pp. 98 ss.), de cómo puede ser fundamentada una infracción de deber tratándose de incapaces de culpabilidad o de quienes se encuentran en error de prohibición: la evitabilidad presupone una motivación dominante de conformidad con la norma. La corriente distinción entre injusto y culpabilidad hace posible una solución sin dificultad alguna: en el nivel del injusto ha de determinarse si el autor exhibe el conocimiento necesario (y la capacidad física) para evitar la realización del tipo - en caso de que él lo hubiese querido-. En la culpabilidad ha de preguntarse si hay razones por las cuales él no pudiera formarse la correspondiente intención o bien no tuviera que hacerlo (exculpación). Así, la motivación dominante es dada por supuesta en el injusto y solo negativamente comprobada en la culpabilidad. Formalmente, en el derecho penal la culpabilidad se postula por vía de hipóstasis; su comprobación positiva no es una pregunta jurídica, al respecto también KINDHÄUSER (1990), pp. 407, 415 ss.

10 Más de cerca Puppe (1992), pp. 35 ss., con ulteriores referencias; cfr. También PÉREZ-BARBERÁ (2013), pp. 454, 467 ss.

$11 \mathrm{Si}$ acaso este pronóstico es objetivamente acertado o no, da igual. El fundamento de la imputación a título de dolo es, exclusivamente, el saber del autor actualmente reflejado en la concreta situación del hecho.

12 CELSus: Digesto, 50.17.185.
} 
Pero del principio de que el conocimiento faltante exonera, el derecho penal hace excepciones. ${ }^{13}$ Una persona queda privada de invocar su actual incapacidad para actuar de modo adecuado a la norma, si esta incapacidad, a su vez, hubiese sido evitable, y precisamente en caso de que la persona hubiese tenido que preocuparse de asegurar la medida esperada de capacidad de seguimiento de la norma. Así, en este caso se ve reemplazado el criterio fáctico de imputación del conocimiento actual en pos de la evitabilidad de la realización del tipo por un criterio normativo. Puesto que esta forma de imputación carga a la persona respectiva por medio de una subrogación normativa, ella tiene que consistir en una decepción, por parte de esa misma persona, de la confianza puesta en su fidelidad al derecho. La incapacidad actual de evitar la realización del tipo ha de ser expresiva, entonces, de una contradicción de la norma merecedora de pena. Esta es -en el nivel del tipo- la situación de la imprudencia.

Todavía en los proyectos de reforma del Código Penal alemán ${ }^{14}$ de comienzos del siglo veinte se definía la imprudencia como la falta de observancia del cuidado esperable del autor en las circunstancias dadas, conducente a una falta de previsión de la realización del tipo delictivo o bien a una confianza infundada en su no realización. ${ }^{15}$ Similarmente, el Tribunal Imperial Supremo, máximo tribunal de revisión de la Alemania de aquel entonces, en una decisión fundamental del año mil ochocientos ochenta y cuatro, veía ya la esencia de la imprudencia "en un error vencible y reprochable acerca de la causalidad de la acción". ${ }^{16}$ Sin embargo, en la dogmática contemporánea se encuentran extendidos planteamientos que, por ejemplo, interpretan la imputación a título de imprudencia como un (sub-) caso de la imputación objetiva, ${ }^{17}$ e incluso se sostiene la tesis de que la imputación a título de dolo y la imputación a título de imprudencia implicarían en igual medida la infracción de un deber de cuidado. ${ }^{18}$

2. La razón para estas diferencias en la comprensión de la imprudencia se encuentra, a mi juicio, en una sustitución terminológica del objeto del cuidado, y no en una desviación de los criterios fundamentales para la imputación a título de imprudencia. Por esta razón parece útil esclarecer la terminología empleada en un caso de ejemplo lo más simple posible. En el marco de unos trabajos de remodelación, A pinta el muro externo de una casa, encontrándose parado sobre un andamio. Con el pie, él golpea un tarro de pintura, el que cae y lesiona al peatón $\mathrm{P}$ en un hombro.

\footnotetext{
${ }^{13}$ Cfr. también $\iint 17$ y 35 del Código Penal alemán. La evitabilidad deja intacto el hecho de que el autor, al momento de la realización del tipo, no tenía conocimiento de la ilicitud o se imaginaba estar en una situación de estado de necesidad.

14 Así el $\int 18$ I del proyecto de 1962.

15 Similarmente el \6 I del Código Penal austríaco; véase también el \18 III del Código Penal suizo de 1937.

${ }^{16}$ RGSt 9, 422 (424); véase también RGSt 56, 343 (349 s.); 61, 318 (320); 67, 12 (18); FRANK, \ 59 nota VIII 4; MEZGER (1949), \ 46 III.

${ }^{17}$ Una nueva revisión del problema en DEHNE-NIEMANN (2012), pp. 89 ss.

18 A modo de ejemplo PUPPE (2013), Nomos Kommentar StGB, ante \ 13 n.m. 154 s.
} 
En este ejemplo, como resultado (jurídico-penalmente relevante) solo viene en consideración la lesión de P. El acaecimiento de este resultado puede ser causalmente explicado, ceteris paribus, por el fuerte impacto del tarro sobre el hombro de P. Puesto que la caída del tarro a su vez fue condicionada, ceteris paribus, por el movimiento corporal de A, cabe decir que A, por la vía de haber pateado el tarro, produjo la lesión de P. Objetivamente, estos son los presupuestos de un comportamiento típico indicado en el \$223 (o bien en el \$230) del Código Penal alemán. Si adicionalmente uno entiende por un riesgo el complejo de condiciones que con una cierta probabilidad puede causar, ceteris paribus, un resultado, entonces el golpe de pie dado al tarro de pintura también puede ser visto como riesgoso en relación con una lesión corporal. Puesto que el concreto resultado de lesión solo se deja explicar, por su parte, en consideración del tarro de pintura golpeado por A, el riesgo creado por A se ha realizado - en el sentido de la teoría de la imputación objetiva- en el resultado de lesión de P. En cambio, el golpe de pie dado al tarro de pintura es independiente de los criterios de imputación de la lesión corporal a título de dolo e imprudencia; aquel solo viene en consideración como objeto de la imputación subjetiva. ${ }^{19}$

Parece tener asimismo poco sentido designar el golpe sobre el tarro de pintura como la infracción de una exigencia de cuidado. Si el cuidado esperado de A consistiera en no patear el tarro de pintura, entonces la norma de cuidado aquí relevante no sería más que una paráfrasis, funcionalmente superflua, de la norma de comportamiento, que prohíbe causa una lesión de P con el golpe del tarro de pintura. En la terminología del derecho civil, que coincide con el uso más generalizado del lenguaje, la imprudencia se define como la falta de adopción del cuidado requerido en el tráfico ( $\mathbb{S} 267$ del Código Civil alemán), esto es, como omisión. El golpe de pie (activo) dado al tarro de pintura difícilmente puede ser entendido como la omisión de una exigencia de cuidado.

El cuidado es una manera de comportarse, a saber, con cautela, y quien actúa descuidadamente no trae a efecto esta prestación. El reproche de un déficit de cuidado se refiere a que el agente o bien no ha alcanzado su fin en lo absoluto, o bien no lo ha alcanzado correctamente, porque él ha omitido las medidas que lo habrían capacitado para alcanzar ese fin en la medida deseada. Aquí el fin puede encontrarse o bien en la producción de un evento deseado o en la evitación de un evento indeseado. Si el resultado es deseado, entonces la caracterización del comportamiento como descuidado significa que el agente ha procedido de una manera que afecta o aun frustra el éxito. Quien descuidadamente vierte un líquido costoso, en referencia a la falta de cuidado no es reprochado por haber vaciado el líquido -eso precisamente lo puede o debe hacer-, sino por no haberlo vertido

19 Acerca de la significación del resultado para el injusto SCHÜNEMANN (1975), pp. 511 s.; del mismo (1982), pp. 60 ss., también en cuanto a los demás criterios de la constitución objetiva del injusto, antepuestos a la imputación subjetiva, por ejemplo la autopuesta en peligro y la conexión de finalidad de protección. 
cuidadosamente -esto es, de la manera de él esperada- de modo tal de no derramar parte de su contenido. Si, por el contrario, el resultado no ha de acaecer, entonces el reproche de una falta de cuidado significa que el agente no mantuvo precaución en la forma de él esperada para así impedir que él condicionara el respectivo resultado. Quien en virtud de una falta de cuidado vierte un líquido costoso, no debía o podía verterlo y es hecho responsable por su pérdida, por no haber sido suficientemente precavido para impedir el derrame del líquido.

En ambas variantes de significado la falta de cuidado se refiere siempre a un déficit, a una preocupación omitida, a algo que fue dejado sin atención. Usualmente ello es aclarado por el hecho de que el fracaso en el objetivo deseado o la falta de evitación del resultado indeseado es reconducido a una falta de preocupación mediante la expresión "en virtud de" o de alguna fórmula semánticamente equivalente.

3. En referencia ahora al derecho penal: si la causación de un resultado típico es caracterizada como contrariedad a cuidado, entonces se confunde el comportamiento a ser evitado con la falta de preocupación por su evitación. En vista del caso inicial, empero, hay una diferencia considerable entre decir que $A$ ha lesionado a $\mathrm{P}$ a través de una patada descuidada al tarro de pintura y decir que $\mathrm{A}$ ha lesionado a $\mathrm{P}$ a través de una patada al tarro de pintura en virtud de una falta de cuidado. En el primer caso, el reproche de falta de cuidado significa que A habría tenido que patear el tarro, pero efectuó el golpe sin el suficientemente cuidado; en el segundo caso, el reproche de falta de cuidado significa que A habría podido evitar patear el tarro de haber aplicado el cuidado necesario. Evidentemente, con la falta de cuidado aquí solo puede estar pensándose en la omisión de una medida para la evitación del golpe al tarro.

De acuerdo con ello, la patada al tarro dada por A - uno puede designar esto como la creación de un riesgo típico- tiene que ser la causa de la lesión de $\mathrm{P}$, que en igual medida puede ser objeto de una imputación a título de dolo o de imprudencia. Habría que hablar de una realización dolosa del hecho si A hubiese sido actualmente capaz de evitación, esto es, hubiese pateado el tarro conscientemente, no obstante haber advertido que por esa vía él probablemente lesionaría al peatón P. Si A no advirtió, empero, que a través del movimiento de su pierna él podía golpear el tarro de pintura y así lesionar a $\mathrm{P}$, entonces él tampoco habrá advertido que él no debía mover su pierna en la manera en cuestión, para así evitar una lesión de $\mathrm{P}$ por medio de la caída del tarro. Sin embargo, A no puede apelar a su falta de conocimiento, en principio exonerante, porque él tiene que responder de este déficit en virtud de su falta de cuidado. De quien se mueve en un ámbito de riesgo se espera que precavidamente adopte medidas para neutralizar el riesgo, es decir: que sujete objetos muebles del andamio o que se desplace con máxima cautela. 
Quien no adopta medidas de este tipo, empero, todavía no causa por esa vía resultado alguno. Pues por el solo hecho de comportarse descuidadamente, A aún no lesiona a alguien. El objetivo del cuidado consiste exclusivamente en ponerse en posición de evitar la causación de la lesión corporal. Si A hubiese alcanzado este objetivo, entonces todavía estaría abierta su decisión de seguir efectivamente la norma. Si se asume que A se mueve por el andamio prestando máxima atención y reconoce así que con una patada al tarro de pintura él puede lesionar a $\mathrm{P}$, entonces también sería posible que él -en vez de evitar semejante movimientopateara ahora conscientemente el tarro de pintura, para así lesionar a (su odiado) P. Ciertamente, A no puede negar la causalidad de su golpe efectivamente dado al tarro con el argumento de que él también en el caso de haber observado el cuidado requerido $-\mathrm{y}$ entonces: conscientemente-habría lesionado a P. Pues la imputación jurídico-penal tiene lugar en el marco de un mundo normativamente ordenado, en el cual solo el comportamiento conforme a derecho, y no contrario a derecho, puede excluir la responsabilidad. ${ }^{20}$

4. Que uno tenga que ejecutar u omitir determinadas acciones, para así poder ejecutar u omitir otras acciones, es un dato evidente de la configuración de la vida cotidiana. La distancia del objetivo en cuestión puede ser más o menos amplia, así como requerir más o menos acciones intermedias. Un ejemplo sencillo: A quiere colgar un cuadro. Para ello, él tiene que martillar un clavo en la pared. Para poder martillar un clavo en la pared, él tiene que conseguir un clavo y un martillo, y así sucesivamente. Cada una de estas acciones sirve para que A quede en posición de ejecutar otras acciones, causalmente independientes de aquellas. En tal medida, cada una de estas acciones puede ser vista como una acción auxiliar para las posteriores acciones. En cambio, la acción que condiciona el resultado final que se persigue como objetivo -aquí: el colgar del cuadro- puede ser caracterizada, relativamente a estas acciones auxiliares, como acción principal.

También la conexión entre una acción principal y una acción auxiliar, así como entre múltiples acciones auxiliares particulares, se deja explicar con ayuda del silogismo práctico. ${ }^{21}$ De cara al caso del ejemplo, esto significa lo siguiente:

Premisa mayor: Una persona P quiere hacer v.

Premisa menor: P asume que ella solo puede hacer v, si ella hace w.

Conclusión: Entonces, P tiene que hacer w.

La conclusión indica nuevamente una acción, cuya ejecución es prácticamente necesaria, en relación con el estado de conocimiento de $\mathrm{P}$ según la premisa menor, para poder realizar la intención-de-acción indicada en la premisa mayor. Para hacer aprovechable el silogismo práctico que tiene por objeto dos acciones vinculadas entre sí por necesidad práctica en la dogmática jurídico-penal -por

20 Brevemente al respecto KINDHÄUSER (2012), pp. 134, $146 \mathrm{s.}$

${ }^{21}$ VON WRIGHT (1977), pp. 56 s.; cfr. también KINDHÄUSER (1989), pp. 62 ss.;TOEPEL (1992), pp.

34 ss.; VOGEL (1993), pp. 74 ss., en cada caso con referencias ulteriores. 
ejemplo, en la dogmática de la intervención delictiva, en la tentativa o (en nuestro contexto) en la imprudencia- se requiere todavía de diferencias ulteriores. Ante todo, y en referencia a las formas de las posibles acciones auxiliares, quisiera introducir la siguiente distinción:

- Una acción auxiliar que una persona ejecuta u omite para poder realizar un actuar o un omitir contrario a una norma, se denomina "acción preparatoria".

- Una acción auxiliar que una persona ejecuta u omite para poder realizar un hacer o un omitir conforme a una norma, la denomino "acción precautoria".

Se introducen aquí las expresiones cuidado y preparación como términos técnicos, teniendo únicamente a la vista acciones principales conformes o contrarias a la norma respectiva, para así evitar posibles malentendidos. Ejemplos: si A se hace de una pistola, para así disparar sobre $\mathrm{B}$, entonces la obtención de la pistola es una acción preparatoria de la acción antinormativa consistente en dar muerte a $\mathrm{B}$. Si habiendo fuerte neblina, en cambio, A conduce su automóvil en marcha lenta, para estar en condiciones de frenar a tiempo en caso de que un peatón aparezca en la vía, entonces es esta una acción precautoria respecto de la evitación, con arreglo a la norma, de una causación de lesiones corporales. La tesis que, en relación con la imprudencia, resulta de estas reflexiones preliminares parece seguirse de suyo: las exigencias de cuidado se refieren a acciones precautorias que una persona fiel a derecho y que decide racionalmente tiene que adoptar para quedar en posición de evitar la realización de un tipo de delito.

5. De ser acertadas estas consideraciones, resulta que la distinción entre norma de comportamiento y exigencia de cuidado es de la mayor importancia dogmática -y en las consecuencias, también de la mayor importancia práctica-. El deber que se sigue de la norma de comportamiento tiene por objeto la evitación de una realización del tipo. Tratándose de un delito doloso, el autor infringe este deber, porque él habría podido evitar la realización del tipo (representada) en virtud de su conocimiento (y capacidad física) disponible. Tratándose de un delito imprudente, el autor infringe el deber porque, de haber observado el cuidado de él esperado, él habría podido adquirir el conocimiento y (en la omisión:) la capacidad física necesarios y evitar la realización del tipo. La norma de comportamiento indica lo que ha de ser evitado, las exigencias de cuidado son el conjunto de las precauciones esperadas en pos de la evitación.

En el caso ya mencionado, tanto el deber de evitar la lesión corporal de otro ser humano como la exigencia de cuidado de moverse cautelosamente sobre el andamio son proposiciones de deber-ser. Pero ambas normas tienen una diferente función en la constitución dogmática del hecho punible. La evitación del comportamiento lesivo (el golpe de pie dado al tarro de pintura) es el deber resultante de la prohibición de lesionar corporalmente a otro, esto es, una acción 
principal debida. En cambio, moverse sin cautela sobre un andamio no es, por sí mismo, un comportamiento prohibido, sino la omisión de una acción precautoria consistente en moverse de un modo que haga posible la evitación de un comportamiento lesivo. La falta de atención en cuanto a precaver movimientos riesgosos se vuelve jurídico-penalmente recién si A causa, en primer lugar, una lesión mediante su comportamiento y la observancia de la atención esperada lo hubiese capacitado, en segundo lugar, para evitar la causación de una lesión, esto es, para dar seguimiento a la prohibición de lesionar corporalmente a otro.

Por ello, ha de distinguirse con la mayor exactitud entre la evitación, conforme a deber, de un comportamiento prohibido, por un lado, y la preocupación, adecuada al cuidado esperado, por la capacidad de evitación conforme a deber, por otro. La prohibición de lesionar corporalmente a otro es un imperativo categórico; este tiene que ser seguido incondicionalmente. La exigencia de cuidado, por el contrario, es un imperativo hipotético; este solo tiene que ser seguido bajo la condición de que alguien quiera estar en posición de seguir un imperativo categórico. Este imperativo hipotético de la exigencia de cuidado solo tiene la consecuencia de que su no seguimiento puede fundamentar la imputación, mientras que su seguimiento conduce a una exclusión de la imputación. ${ }^{22}$

Para quedarnos en el ejemplo: si A se mueve sobre el andamio sin golpear con su pie el tarro de pintura y por esa vía lesionar a alguien, es enteramente irrelevante si, sobre el andamio, A se ha comportado con la mayor precaución o bien de modo crasamente descuidado. El moverse cautelosamente sobre el andamio no es, precisamente, un imperativo categórico; como tal, uno no está obligado a hacer esto por mor de sí mismo. Pero si A patea el tarro de pintura y por esa vía lesiona a $\mathrm{P}$, entonces se cumple la condición bajo la cual la exigencia de cuidado produce su efecto. Si A hubiese podido evitar patear el tarro de pintura de haber observado la atención esperada, entonces, teniendo que responder de la falta de observancia del cuidado de él esperado, él no puede apelar a su falta de conocimiento de las consecuencias de su movimiento conducente a una lesión corporal. La infracción de la exigencia de cuidado es, entonces, lo que normativamente subroga el déficit de conocimiento.

\section{Acerca de la fundamentación de las exigencias de cuidado}

1. En la medida en que una norma de comportamiento ha de ser seguida en ámbitos vitales en los cuales un riesgo potencial puede provenir exclusivamente de un individuo, las exigencias de cuidado se dirigen, en principio, a la neutralización

22 El legislador puede prohibir categóricamente, autonomizándolas, formas de comportamiento que según la experiencia limitan la evitabilidad de lesiones de bienes jurídicos. Ejemplo de ello es la ebriedad en el tráfico vial ( $\int 316$ del Código Penal alemán). Semejantes contrariedades a cuidado transformadas en hechos punibles autónomos constituyen entonces delitos de peligro abstracto, aunque pueden seguir sirviendo como normas de cuidado en la imputación a título de imprudencia, por ejemplo tratándose de un homicidio imprudente en el tráfico rodado. 
más segura posible de los riesgos respectivos. A modo de ejemplo: Quien, como en el caso inicial, se mueve sobre un andamio tiene que preocuparse cabalmente de no pasar a llevar (de modo no advertido) cualquier objeto que pueda caer. Según el caso, de entre un conjunto de medidas de precaución él puede escoger la que le sea más cómoda, siempre y cuando se encuentre asegurada la eficiencia requerida. $\mathrm{Y}$ no deben ser asumidos riesgos que en tales ámbitos vitales no puedan ser enteramente dominados. La falta de cuidado se encuentra aquí ya en la errónea estimación de poder desempeñarse de entrada en este ámbito de riesgo.

En cambio, en ámbitos en los que emergen riesgos recién mediante la interacción social o en los que las interacciones mismas resultan riesgosas, el individuo no tiene siquiera la posibilidad de asegurar las condiciones de los complejos de riesgo relevantes que de él provengan; el tráfico vial motorizado es aquí paradigmático. En tales ámbitos, los riesgos tienen que ser reducidos por reglas normativas de comportamiento, en cuya observancia general los participantes en la interacción han de poder confiar. ${ }^{23}$ Esta confianza recíproca sustituye el conocimiento recíprocamente faltante. Así, en el caso normal el conductor A no sabe si el peatón que tiene en frente un semáforo en luz roja cruzará o no la calzada por la cual A se desplaza; pero en su estimación de los riesgos asociados a su conducción, A puede partir de la base de que el peatón $\mathrm{P}$ recién atravesará la calle cuando tenga luz verde. Si, no obstante, $\mathrm{P}$ cruza la calle con luz roja y es impactado por A, entonces a este no podrá reprocharse que, para evitar el riesgo de una lesión de $\mathrm{P}$, él habría tenido gravosamente que incluir en su cálculo la posibilidad de que $\mathrm{P}$ cruzase la calle y así haber conducido en marcha lenta. Por otra parte, A puede asimismo contar con que $\mathrm{P}$ parte de la base de que A asumirá que él $(\mathrm{P})$ se quedará sin cruzar ante la luz roja, sin conducir en marcha lenta para así dejarle (a P) cruzar la calle.

Estas recíprocas expectativas contrafácticas conducen a un así llamado riesgo permitido. Puesto que aquel que puede legítimamente confiar en el comportamiento correcto de sus compañeros de interacción, no actúa de modo contrario a cuidado, a pesar del déficit de conocimiento, cuando asume los correspondientes riesgos, las realizaciones de riesgos de aquí resultantes no son imputables como producciones imprudentes de menoscabos. Sería una autocontradicción de parte del derecho que este permitiese, por una parte, formas de comportamiento que conducen a una disminución de la capacidad de acción, pero considerara esta incapacidad como descuido fundante de responsabilidad.

2. Como último problema, se plantea todavía la pregunta de si el estándar de cuidado propio del ciudadano leal al derecho y capaz de decisión racional ha de ser aplicado a una persona ficticia o al concreto autor. A modo de ejemplo: $\mathrm{V}$, el conductor de un vehículo de carga con remolque, adelanta al ciclista $\mathrm{C}$ en un camino rural, quien en razón de su elevada alcoholización no es capaz de

23 Acerca de los criterios determinantes de la ponderación de intereses, cfr. solo SCHÜNEMANN (1975), pp. 575 ss. 
controlar su bicicleta y es letalmente impactado por el remolque. Si V se ha hecho punible según el \222 del Código Penal alemán, depende de si a él puede imputarse su comportamiento causal para la muerte de $\mathrm{C}$ como infracción de deber en virtud de una falta de cuidado.

El cuidado necesario se refiere a la evaluación del riesgo adecuada a la situación y a las medidas a ser adoptadas para la evitación de la causación de un desenlace mortal: además de la consideración del estado de las calles y del tiempo, tratándose de un adelantamiento se plantea decisivamente la cuestión de qué control del vehículo cabe esperar de un ciclista al pasar por su lado un camión de carga. Si en atención a las consideraciones determinantes resulta que una distancia de seguridad de un metro y medio posibilitaría un adelantamiento probablemente no peligroso, entonces $\mathrm{V}$ se mueve dentro del riesgo permitido si él mantiene a lo menos esta distancia. Si no obstante ello él causa la muerte de C, entonces la no evitación de este resultado no le es imputable como infracción de deber en virtud de una contrariedad a cuidado.

Con ello, en este caso la determinación de las exigencias de cuidado se orienta esencialmente a la evaluación de las capacidades del ciclista. Puesto que se trata aquí de un ámbito de interacción en el que la neutralización de los riesgos relevantes también depende de la confianza recíproca en el aseguramiento de las capacidades y los estándares de comportamiento normativamente exigidos, el conocimiento faltante en cuanto al efectivo control de la bicicleta por parte del concreto ciclista $\mathrm{C}$ puede ser reemplazado con valores estandarizados. En las consecuencias, con ello, en la imputación aparece el riesgo permitido normativamente determinado en lugar del riesgo no susceptible de ser ex ante correctamente pronosticado en el caso normal. Para el caso del ejemplo significa esto que bajo una prognosis de riesgo adecuada al cuidado puede partirse de la base de que $C$ está suficientemente sobrio para poder reaccionar del modo habitual en el tráfico.

Ahora bien, según la concepción dominante no rige el principio de confianza si el compañero de interacción en cuestión manifiestamente no se ajusta a los valores estandarizados. Pues el principio de confianza debe servir a la adecuada neutralización de riesgos y no incrementar, por ejemplo, el riesgo de daño. Si en el caso del ejemplo $\mathrm{V}$ reconoce por la calle a $\mathrm{C}$ como su compañero de barra, que un cuarto de hora antes que él había abandonado el local, tambaleándose en estado de alta alcoholización, entonces en la prognosis del riesgo ya no puede estarse a la sobriedad en general esperable de C. Ahora, una prognosis de riesgo cuidadosa tiene que considerar la ebriedad de $\mathrm{C}$, lo que significa que $\mathrm{V}$-según cuál sea la situación vial- o bien ha de mantener una distancia de seguridad mayor o bien ha de abstenerse de toda maniobra de adelantamiento. 
En este sentido, la imprudencia individual no puede ser confundida con un actuar según parámetros propios. Tanto las reglas de imputación como las reglas de comportamiento correcto se encuentran antepuestas al destinatario de la norma. Dolo no es aquello que el autor tiene por doloso, y cuidado no es aquello que el autor tiene por cuidadoso. Tanto el dolo como el cuidado son conceptos objetivos, determinados en su intensión [o sentido] por medio de la terminología jurídica, cuya referencia se orienta en la aplicación a datos cognitivos y de naturaleza psíquica del agente. Si alguien actúa dolosamente depende de si él actúa con el conocimiento que según la respectiva definición puede ser designado como fundante de dolo, y si alguien actúa descuidadamente depende si él se comporta de una manera que según la respectiva definición ha de ser considerada como una falta de observancia de las exigencias de cuidado puestas sobre su proceder. El estándar relevante para la determinación del cuidado requerido siempre ha de ser referido a un destinatario de la norma fiel a derecho y escrupuloso. En la prognosis de riesgo orientada a la óptima protección de bienes jurídicos, este destinatario de la norma solo ha de ser dotado de los conocimientos del concreto autor. El reproche de que el autor -de haber observado el cuidado de él esperado- habría podido y tenido que saber algo determinado solo se sostiene si el conocimiento efectivamente existente daba base suficiente para obtener el conocimiento faltante o bien para omitir un actuar sin llenar previamente las lagunas de conocimiento. ${ }^{24} \mathrm{El}$ compendio de cuidado cotidiano quizá más importante para efectos prácticos, la ordenanza del tráfico vial, establece en el $\ 1$, apartado 2, el principio que modifica todas las reglas placativas que le siguen según el específico conocimiento de los peligros de los participantes en el tráfico: la participación en el tráfico vial exige atención permanente y consideración recíproca.

\footnotetext{
${ }^{24}$ STRUENSEE (1987), pp. 97, 99 ss.
} 


\section{BIBLIOGRAFÍA}

* Celsus: Digesto de Justiniano. 50.17.185.

* Dehne-NiemanN, Jan (2012): “Sorgfaltswidrigkeit und Risikoerhöhung” en Goltdammer's Archivfür Strafrecht.

* Essler, Wilhelm (1969): Einführung in die Logik, $2^{\text {a }}$ ed., Stuttgart, E. Kröner.

* Frank, Reinhardt (1931): Das Strafrechtfür das Deutsche Reich, $18^{a}$ edición.

* Holdvon Ferneck, Alexander (1903): Die Rechtswidrigkeit. Eine Untersuchungzu den Allgemeinen Lehren des Strafrechtes, Tomo I, Gustav Fischer, Jena.

* HruschKA, Joachin (1991): "Verhaltensregeln und Zurechnungsregeln" en Rechtstheorie 22, Dunker\&Humblot, Berlín.

* KANT, Immanuele (1797): Die Metaphysike der Sitten (Erster Theil).

* KindHÄUSER, Urs (2012): “Zurechnungbeialternativer Kausalität”, en Goltdammer's Archivfür Strafrecht.

(1989): Gefährdungals Straftat, Vittorio Klostermann, Frankfurt am Main.

(2013): Strafrecht Allgemeiner Teil, $\sigma^{a}$ edición, Nomos, Baden-Baden.

(1990): "Zur Unterscheidung von Tat- und Rechtsirrtum" en Goltdammer's Archivfür Strafrecht.

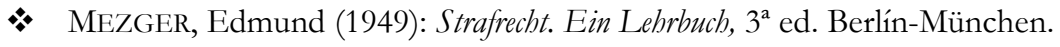

* PÉrez-BArberÁ, Gabriel (2013): "Vorsatzals Vorwurf" en Goltdammer's Archivfür Strafrecht.

* PupPe, Ingeborg (1992): Vorsatz und Zurechnung, Heidelberg, Decker \& Müller. (2013): Nomos Kommentar StGB, $4^{\mathrm{a}}$ ed., Nomos, Baden-Baden.

* RaZ, Joseph (2006): Praktische Gründe und Normen, SuhrkampVerlag, Frankfurt am Main.

* Schünemann, Bernd (1975): "Moderne Tendenzen in der Dogmatik der Fahrlässigkeitsund Gefährdungsdelikte" en Juristische Arbeitsblätter.

(2002): "Unzulänglichkeiten des Fahrläassigkeitsdelikts in der modernen Industriegesellschaft - Eine Bestandsaufnahme", en Gedächtnisschriftfür Dieter Meurer, De Gruyter Recht, Berlín.

* Struensee, Eberhard (1987): “Objektive Zurechnung und Fahrlässigkeit”, en Goltdammer's Archivfür Strafrecht.

* TOEPEL, Friedrich (1992): Kausalität und Pflichtwidrigkeitszusammenhangbeimfahrlässigen Erfolgsdelikt, Dunker \& Humblot, Berlín.

* Vogel, Joachim (1993): Norm und Pflichtbei den unechten Unterlassungsdelikten, Duncker \& Humblot, Berlín.

* Von Wright, Georg (1977): Handlung, Norm und Intention, Walter de Gruyter, Berlín. 